ARTICLE

Received 4 Apr 2014 | Accepted 27 Jun 2014 | Published 1 Aug $2014 \quad$ DOl: 10.1038/ncomms5553

\title{
Accelerated discovery of cathode materials with prolonged cycle life for lithium-ion battery
}

Motoaki Nishijima1', Takuya Ootani ${ }^{1}$, Yuichi Kamimura', Toshitsugu Sueki ${ }^{1}$, Shogo Esaki ${ }^{1}$, Shunsuke Murai ${ }^{2}$, Koji Fujita ${ }^{2}$, Katsuhisa Tanaka ${ }^{2}$, Koji Ohira ${ }^{3}$, Yukinori Koyama ${ }^{3} \&$ Isao Tanaka ${ }^{3}$

Large-scale battery systems are essential for efficiently utilizing renewable energy power sources from solar and wind, which can generate electricity only intermittently. The use of lithium-ion batteries to store the generated energy is one solution. A long cycle life is critical for lithium-ion battery when used in these applications; this is different from portable devices which require 1,000 cycles at most. Here we demonstrate a novel co-substituted lithium iron phosphate cathode with estimated $70 \%$-capacity retention of 25,000 cycles. This is found by exploring a wide chemical compositional space using density functional theory calculations. Relative volume change of a compound between fully lithiated and delithiated conditions is used as the descriptor for the cycle life. On the basis of the results of the screening, synthesis of selected materials is targeted. Single-phase samples with the required chemical composition are successfully made by an epoxide-mediated sol-gel method. The optimized materials show excellent cycle-life performance as lithium-ion battery cathodes.

\footnotetext{
${ }^{1}$ Corporate Research and Development Division, Materials and Energy Technology Laboratories, SHARP Corporation, Tenri, Nara 632-8567, Japan.

${ }^{2}$ Department of Material Chemistry, Kyoto University, Nishikyo, Kyoto 615-8510, Japan. ${ }^{3}$ Department of Materials Science and Engineering, Kyoto University, Sakyo, Kyoto 606-8501, Japan. Correspondence and requests for materials should be addressed to M.N. (email: nishijima.motoaki@sharp.co.jp) or to I.T. (email: tanaka@cms.mtl.kyoto-u.ac.jp).
} 
A mong the range of lithium-ion battery (LIB) cathode materials, $\mathrm{LiFePO}_{4}$ (LFP) has advantages in cost, safety and cycle life as compared with others ${ }^{1,2}$. When renewable energy-storage applications are considered, however, the cycle life of LFP needs to be further improved. Cycle life is typically defined as the number of complete charge/discharge cycles before its capacity falls down to a certain level, say $70 \%$, of its initial value. Our target of the long-life battery is more than $70 \%$ capacity retention after 10,000 cycles. If this target is met then LIB can meet the lifetime cost requirement for their use over 30 years with a daily charge/discharge cycle. The present study aims to develop LFP materials that exhibit prolonged cycle lives by substituting a range of solute elements on the different cation sites of the LFP material.

The selection of suitable solute elements is labour-intensive for two reasons. First, the exploration space is huge when multiple solute elements and a variety of chemical compositions are considered. Second, many different metastable phases often appear depending upon the synthesis and processing conditions, such as synthesis temperature, synthesis routes and so on, even when the chemical composition is fixed. A clear idea of which phase to be targeted is essential before starting the actual synthesis experiments. Discovery of and optimization of materials for a particular application has often been achieved by chance after lengthy trial-and-error iterations, neither by rational exploration of the whole chemical compositional space, nor on the basis of clear design principles. Recently, challenges for accelerated discovery of materials with the aid of information technology have been demonstrated ${ }^{3}$. One of the approaches uses high-throughput screening of material database that is generated by first principles density functional theory (DFT) calculations ${ }^{4-6}$. Thanks to the recent progress of computational power and techniques, a large number of DFT calculations can be performed with the accuracy comparable to experiments. This can be used for high-efficiency material exploration. Another approach is based upon state-of-the-art machine-learning algorithms to search the optimum in the chemical compositional space ${ }^{7}$. A combined approach of both techniques has also been used ${ }^{8,9}$.

The cycle life of LIB cathodes is not a quantity that can be derived by a simple physical model. It is determined by the degradation rate during repeated charge/discharge cycles that is influenced by many different factors. The charge and discharge processes for LFP proceeds via a two-phase reaction, and which inevitably produces interphase boundaries with different lattice parameters ${ }^{10}$. The volume change of crystalline lattice between LFP and fully delithiated FP is $6.5 \%{ }^{1}$. Microcracks are often formed because of the stress inside the LFP cathodes during the repeated charge/discharge cycle, which is widely accepted as the major degradation mechanism of the LFP cathode ${ }^{11}$. The degradation could therefore be retarded by reducing the volume change of the crystalline lattice during the charge/discharge cycle. Here we assume that the relative volume change (RVC) of a compound between fully lithiated and delithiated conditions can be used as the descriptor for the cycle life. We then explore a wide chemical compositional space in order to optimize solute atoms in LFP cathode materials for prolonged LIB cycle life by systematic DFT calculations. On the basis of the results of the screening, synthesis of selected materials can be targeted. After synthesis of single-phase samples with the required chemical composition, excellent cycle-life performance as LIB cathode is confirmed.

\section{Results}

Systematic DFT calculations. In the present study, a large set of DFT calculations is systematically made for many different kinds of solute elements that are substituted on three possible cation sites of LFP. Many experimental and theoretical studies on solute atoms in LFP have been reported since the early work of the aliovalent doping in $\mathrm{LFP}^{12}$. There has been controversy on the capability of the aliovalent doping. History of the debate on the doping can be found in reference ${ }^{13}$. It should be emphasized that they discussed the solubility of single aliovalent dopants and related defect/carrier formation in LFP. The situation is very different from the present study where we treat only cosubstitution of elements to maintain the charge neutrality within the compound. Generally speaking, single aliovalent elements and co-substitution of elements behave differently in wide-gap materials. In the present study, the charge neutrality is maintained by assuming that the formal ionic charges are unchanged. For example, when $\mathrm{Zr}^{4+}$ and $\mathrm{Si}^{4+}$ are incorporated and are located, respectively, at $\mathrm{Fe}^{2+}$ and $\mathrm{P}^{5+}$ sites, two $\mathrm{Si}$ atoms and one $\mathrm{Zr}$ atom are put into the supercell of the DFT calculation. The situation can be expressed as $\left(\mathrm{Zr}_{\mathrm{Fe}}+2 \mathrm{Si}_{\mathrm{P}}\right)$. The chemical compositional space investigated in the present study is shown as 630 cubes in Fig. 1a. DFT calculations are thoroughly made for all possible solute arrangements within the unit cell composed of four formula units of LFP (that is, 28 atoms). The lowest energy structure among them is adopted as the one representing the given chemical composition. An example of the dependence of the energy on the solute arrangement is shown in Fig. 1b. A section of the results obtained from the calculations for the relative volume change between lithiated and fully delithiated materials is shown in Fig. 1a. RVC is defined by $100 \cdot\left(V_{\mathrm{L}}-V_{\mathrm{D}}\right) / V_{\mathrm{L}}$ (\%), where $V_{\mathrm{L}}$ and $V_{\mathrm{D}}$ denote lattice volumes of lithiated and delithiated material LFP, respectively.

According to the series of calculations performed, the effective ways of reducing the RVC are found by double substitutions of LFP with either $\mathrm{Si}^{4+}$ or $\mathrm{Al}^{3+}$ at the $\mathrm{P}$ site and trivalent or tetravalent cations at the $\mathrm{Fe}$ site. Among them, some sets of substitutions show RVC of smaller than 3\%: for example, $\left(\mathrm{Y}_{\mathrm{Fe}}+\mathrm{Si}_{\mathrm{P}}\right),\left(\mathrm{Zr}_{\mathrm{Fe}}+2 \mathrm{Si}_{\mathrm{P}}\right)$ and $\left(\mathrm{Zr}_{\mathrm{Fe}}+\mathrm{Al}_{\mathrm{P}}\right)$. We will focus on the $\left(\mathrm{Zr}_{\mathrm{Fe}}+2 \mathrm{Si}_{\mathrm{P}}\right)$ system, which will be hereafter called $\mathrm{Z} 2 \mathrm{~S}$. Its chemical formula is $\mathrm{Li}\left(\mathrm{Fe}_{1-x} \mathrm{Zr}_{x}\right)\left(\mathrm{P}_{1-2 x} \mathrm{Si}_{2 x}\right) \mathrm{O}_{4}$.

DFT calculations for Z2S with supercells composed of 8 and 16 formula units are additionally made, which corresponds to $x=0.125$ and 0.0625 , respectively. Results of the RVC are shown in Fig. 2(a) together with the trends observed in the mismatch of the (100) planes (bc planes) between lithiated and delithiated materials (Fig. 2b). The planar mismatch is defined by $100 \cdot\left(A_{\mathrm{L}}-A_{\mathrm{D}}\right) / A_{\mathrm{L}}(\%)$, where $A_{\mathrm{L}}$ and $A_{\mathrm{D}}$ denote areas of bc planes in lithiated and delithiated materials, respectively. According to the domino-cascade model by Delmas et al. ${ }^{10}$ for the delithiation mechanism of LFP, the interphase boundaries between LFP and FP prefer (100) planes. A smaller planar mismatch between the planes is therefore expected to be beneficial for retarding the degradation during repeated charge/ discharge cycles.

Both the volume and the planar mismatch decrease linearly with the solute concentration. A possible mechanism for the decrease in the RVC following the substitutions is briefly discussed here. Figure $2 \mathrm{c}$ shows correlations between the RVC of $\mathrm{FeO}_{6}, \mathrm{LiO}_{6}$ and $\mathrm{PO}_{4}$ polyhedra with the lattice RVC for many different substituted materials that have been calculated in the present study. A clear trend can be seen between the lattice RVC and the polyhedral RVC for $\mathrm{FeO}_{6}$ and $\mathrm{LiO}_{6}$. On the other hand, the polyhedral RVC for $\mathrm{PO}_{4}$ is almost unaffected by the lattice RVC. The magnitude of the reduction of the polyhedral RVC is larger in $\mathrm{LiO}_{6}$ than in $\mathrm{FeO}_{6}$, which explains the observed effect with the substituted LFP. As drawn in Fig. 2d, the polyhedral RVC became smaller in $\mathrm{FeO}_{6}$ and larger in $\mathrm{LiO}_{6}$ in the substituted LFP, thereby making the lattice RVC smaller. 


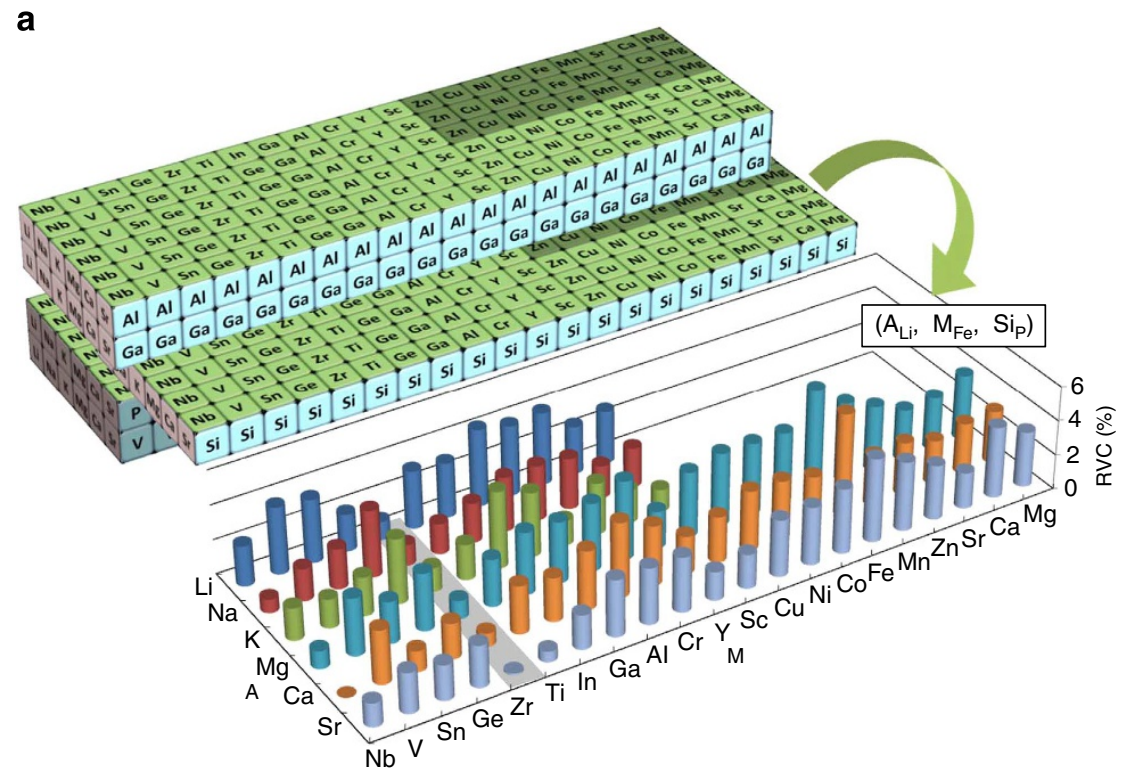

b
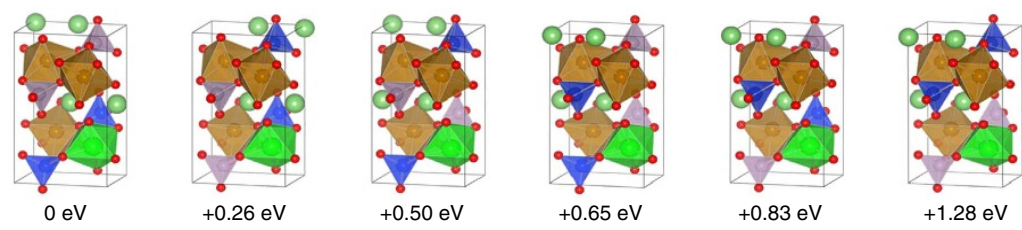

Figure 1 | Theoretical results of co-substituted LFP. (a) Variety of the chemical compositional space investigated in the present study. The shaded area corresponds to chemical compositions that are excluded from the present study, since the charge compensation is not possible within the given supercell. Calculated RVC between lithiated and fully delithiated materials on a $\left(A_{L i}, M_{F e}, S i_{P}\right)$ section is shown together. (b) An example of the dependence of the energy on the solute arrangements for $\left(\mathrm{Li}_{\mathrm{Li}}, \mathrm{Zr}_{\mathrm{Fe}}, \mathrm{Si}_{\mathrm{P}}\right)$, that is, $\mathrm{Z} 2 \mathrm{~S}$ material. The energy is per four formula units of $\mathrm{LFP}$, and relative to the lowest energy arrangement. Orange and green octahedrons, respectively, denote $\mathrm{FeO}_{6}$ and $\mathrm{ZrO}_{6}$. Violet and blue tetrahedrons denote $\mathrm{PO}_{4}$ and $\mathrm{SiO}_{4}$, respectively. Green and red balls, respectively, show Li and O.

Synthesis and characterization of targeted materials. On the basis of the results of the computational screening of the substituted LFP, synthesis experiments were performed for $\mathrm{Li}\left(\mathrm{Fe}_{1-x} \mathrm{Zr}_{x}\right)\left(\mathrm{P}_{1-2 x} \mathrm{Si}_{2 x}\right) \mathrm{O}_{4}$ materials with varying $x$. Initially, the conventional solid-state reaction method was used. Many different procedures, starting materials, synthesis temperatures, atmospheres and durations were tried; however, the production of a single-phase solid-solution material was unsuccessful. We have chosen to use an epoxide-mediated sol-gel method to obtain more intimate mixing of the starting materials. By optimizing the processing parameters, single-phase solid-solution samples were successfully synthesized. Pictures of the sol-gel products and the final powder sample are shown in Fig. 3a,b. Particle diameters using scanning electron microscopy were $\sim 0.1 \mu \mathrm{m}$ in both pristine and co-substituted samples.

Structural analysis by the powder X-ray diffraction (XRD) shows that the samples of $\mathrm{Li}\left(\mathrm{Fe}_{1-x} \mathrm{Zr}_{x}\right)\left(\mathrm{P}_{1-2 x} \mathrm{Si}_{2 x}\right) \mathrm{O}_{4}$ are singlephase up to the value of $x=0.125$. XRD patterns are shown in Supplementary Fig. 1. Figure $3 \mathrm{c}$ shows the result of the Rietveld refinement ${ }^{14}$ of the XRD profile for the $x=0.125$ sample. Only $1 \%$ of the Li site is found to be occupied by $\mathrm{Fe}$ and the $\mathrm{Zr}$ content at the $\mathrm{Fe}$ site is $13 \%$, which satisfactorily agrees to the intended ratio of cations and the mixed quantities. We can therefore conclude that single-phase solid-solution samples of Z2S are successfully synthesized up to $x=0.125$. More details of the XRD analyses were described in Supplementary Note 1.

Electrochemical experiments. We first made experiments using a beaker-type cell with a lithium metal anode. Charge and discharge curves with the Z2S $(x=0.125)$ cathode and the rate of $170 \mathrm{mAg}^{-1}$ (corresponding to $1 \mathrm{C}$ for the pristine cathode) are shown in Fig. 4a. First discharge capacity was $128 \mathrm{mAhg}^{-1}$, which corresponds to $88 \%$ of theoretical capacity $\left(145 \mathrm{mAhg}^{-1}\right.$ for Z2S $(x=0.125)$ cathode). The cells with the pristine and the Z2S $(x=0.125)$ cathodes are compared in Supplementary Fig. 2 of Supplementary Note 2. Both of them exhibit a plateau at the same potential value, $3.4 \mathrm{~V}$, implying that the co-substitution does not affect the redox reaction of $\mathrm{Fe}$ ions significantly. Their rate capabilities are found to be almost the same.

The experimental and calculated lattice parameters of compounds before and after the delithiation are shown in Fig. $4 \mathrm{~b}, \mathrm{c}$ as a function of solute concentration, $x$. The lattice parameters for all three axes show small dependence on $x$ before the delithiation. The dependence is much larger in the delithiated compounds especially for $a$ and $b$ axes. In other words, the presence of the solute elements has a much larger impact on the structure of delithiated compounds.

The experimental lattice RVC and the planar mismatch of bc plane are shown in Fig. 2a,b to compare with the computed values. Satisfactory agreements between experiments and computed results can be seen. The experimental lattice RVC decreases linearly with $x$ from $6.3 \%(x=0)$ to $3.7 \%(x=0.125)$. A similar trend can be observed for the planar mismatch of bc planes. It decreases linearly with $x$ from $1.5 \%(x=0)$ to $0.3 \%(x=0.125)$ by experiments. We can therefore expect that the strain energy at the interphase boundary of LFP/FP can be significantly decreased by the co-substitution of LFP.

The cycle life performance was examined for the Z2S cathode in an aluminium-laminated pouch cell using a natural graphite 
a

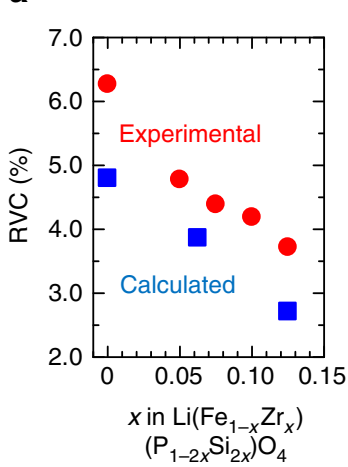

b

d

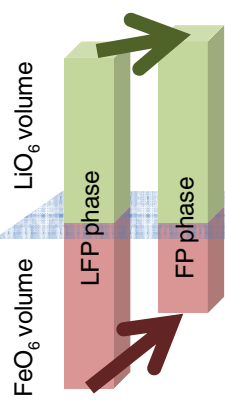

Un-substituted
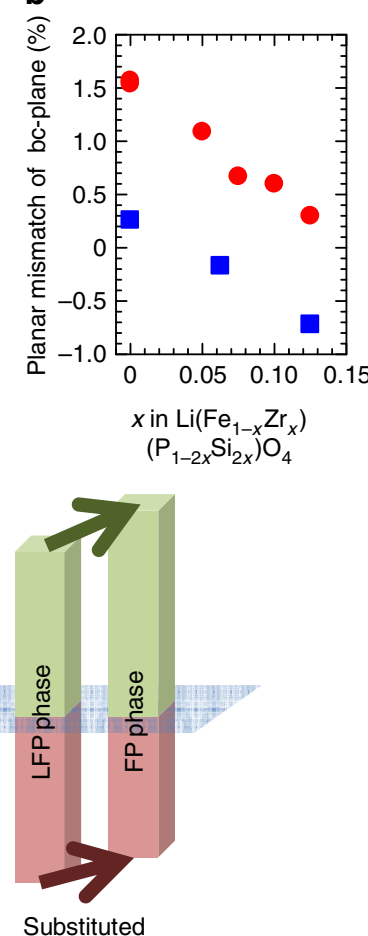

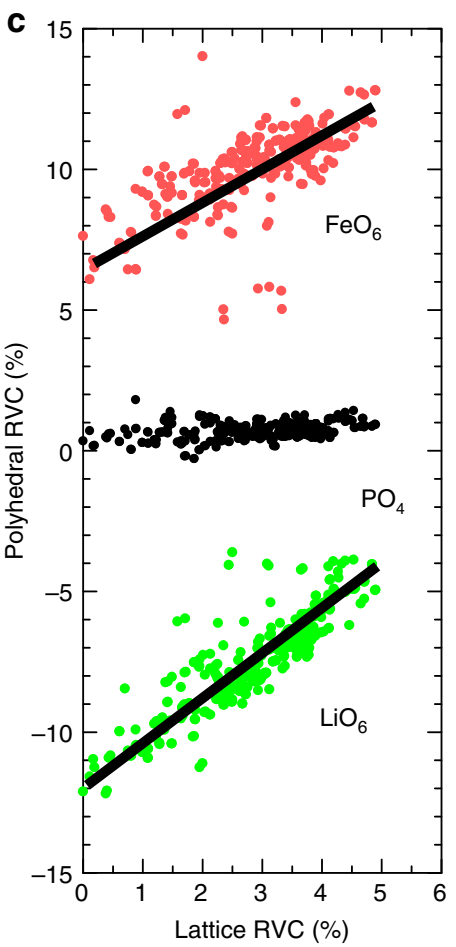

Figure 2 | Effects of solutes on RVC. (a) RVC between lithiated $(\delta=0)$ and delithiated $(\delta=1-x)$ materials for $\mathrm{Li}_{1-\delta}\left(\mathrm{Fe}_{1-x} \mathrm{Zr}_{x}\right)\left(\mathrm{P}_{1-2 x} \mathrm{Si}_{2 x}\right) \mathrm{O}_{4}$. Blue square and red circle denote DFT results and experimental results, respectively. (b) Planar mismatch of (100) planes (bc planes) between lithiated and fully delithiated materials for $\mathrm{Li}_{1-\delta}\left(\mathrm{Fe}_{1-x} \mathrm{Zr}_{x}\right)\left(\mathrm{P}_{1-2 x} \mathrm{Si}_{2 x}\right) \mathrm{O}_{4}$. (c) Correlations between the $\mathrm{RVC}$ of $\mathrm{FeO}_{6}, \mathrm{LiO}_{6}$ and $\mathrm{PO}_{4}$ polyhedra with the lattice RVC for many different substituted materials. (d) Explanation of the solute effects on the lattice RVC.
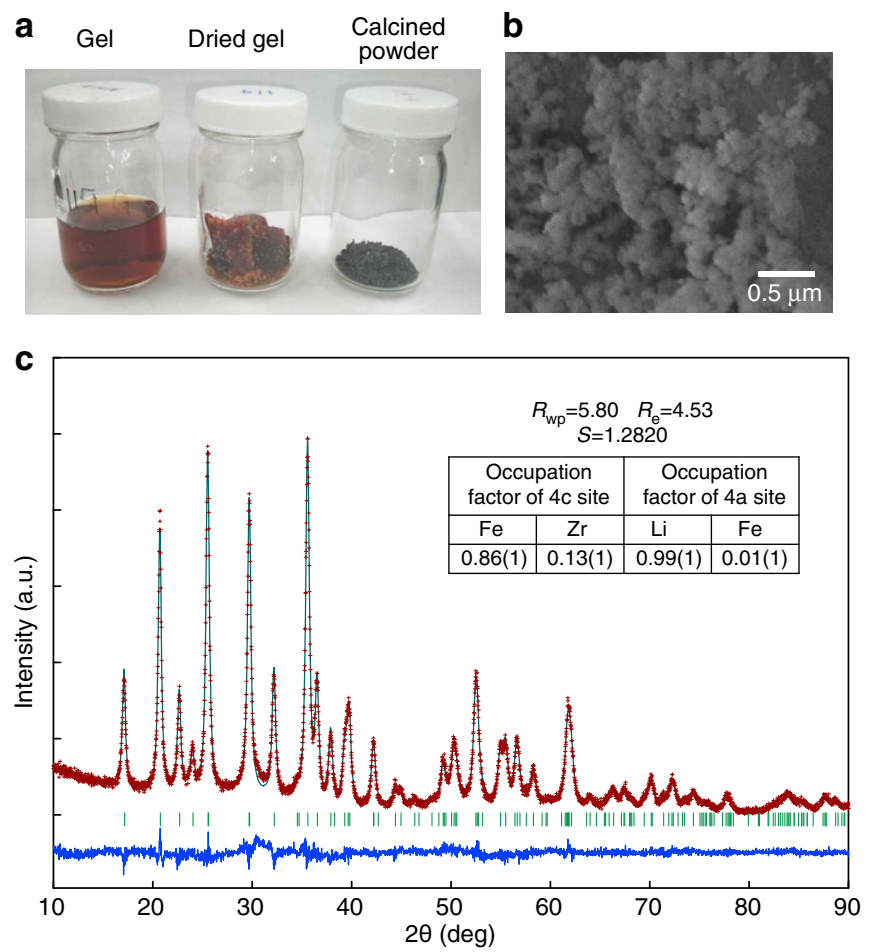

Figure 3 | Synthesis of Z2S co-substituted LFP. (a) Pictures of the gel, dried gel and the final calcined powder for the $\mathrm{Li}\left(\mathrm{Fe}_{1-x} \mathrm{Zr}_{x}\right)\left(\mathrm{P}_{1-2 x} \mathrm{Si}_{2 x}\right) \mathrm{O}_{4}$ sample with $x=0.125$. (b) Scanning electron microscopy image of the calcined powder with $x=0.125$. (c) XRD ( $\mathrm{Cu}-\mathrm{K} \alpha)$ profile and the result of the Rietveld refinement for the $\mathrm{Li}\left(\mathrm{Fe}_{1-x} \mathrm{Zr}_{x}\right)\left(\mathrm{P}_{1-2 x} \mathrm{Si}_{2 x}\right) \mathrm{O}_{4}$ sample with $x=0.125$. anode. A cell with a pristine LFP cathode was prepared for comparison. Charge/discharge cycles of the cells were made between 2.00 and $3.80 \mathrm{~V}$ using a $1 \mathrm{C}$ current rate. The specific capacity of two cells with Z2S $(x=0.050)$ cathode (Cell-A) and pristine cathode (Cell-B) are compared in Fig. 5a. Although the initial capacity of Cell-B with pristine LFP cathode $\left(144 \mathrm{mAh} \mathrm{g}^{-1}\right)$ was higher than that of Cell-A $\left(125 \mathrm{mAh} \mathrm{g}^{-1}\right)$, the capacity fades much faster in Cell-B. As a result, the capacity became larger in Cell-A after 2,100 cycles. The cycle life with $80 \%$ capacity retention was 10,000 cycles for Cell-A, whereas it was 1,800 cycles for Cell-B. This significant increase in cycle life of Cell-A compared with Cell-B can be ascribed to the difference in the cathodes, since all other components of the cell and cell testing are the same. The capacity retention often shows linear decrease with the square root of the number of cycles. Using this empirical relationship, the cycle life observed for $70 \%$ capacity retention can be estimated as 25,000 cycles for Cell-A. This is significantly greater than our target cycle life of $70 \%$ capacity retention of 10,000 cycles. It should be noted that the substitution of $\mathrm{Fe}$ by $\mathrm{Zr}$ inevitably decreases the theoretical capacity because $\mathrm{Zr}$ cannot contribute to the redox reaction under the present condition. However, initial capacity of cathode is not the critical parameter for the large-scale battery systems, contrary to the application to portable devices. The capacity after many cycles, as the result of large initial capacity and slow capacity fading, is crucial.

\section{Discussion}

We have rationally explored a wide chemical compositional space for co-substituted LFP in order to optimize LFP cathode materials for prolonged LIB cycle life. Systematic DFT calculations were performed for a wide range of substituted LFP and FP materials. It was predicted that concurrently substituting LFP on the Fe and 

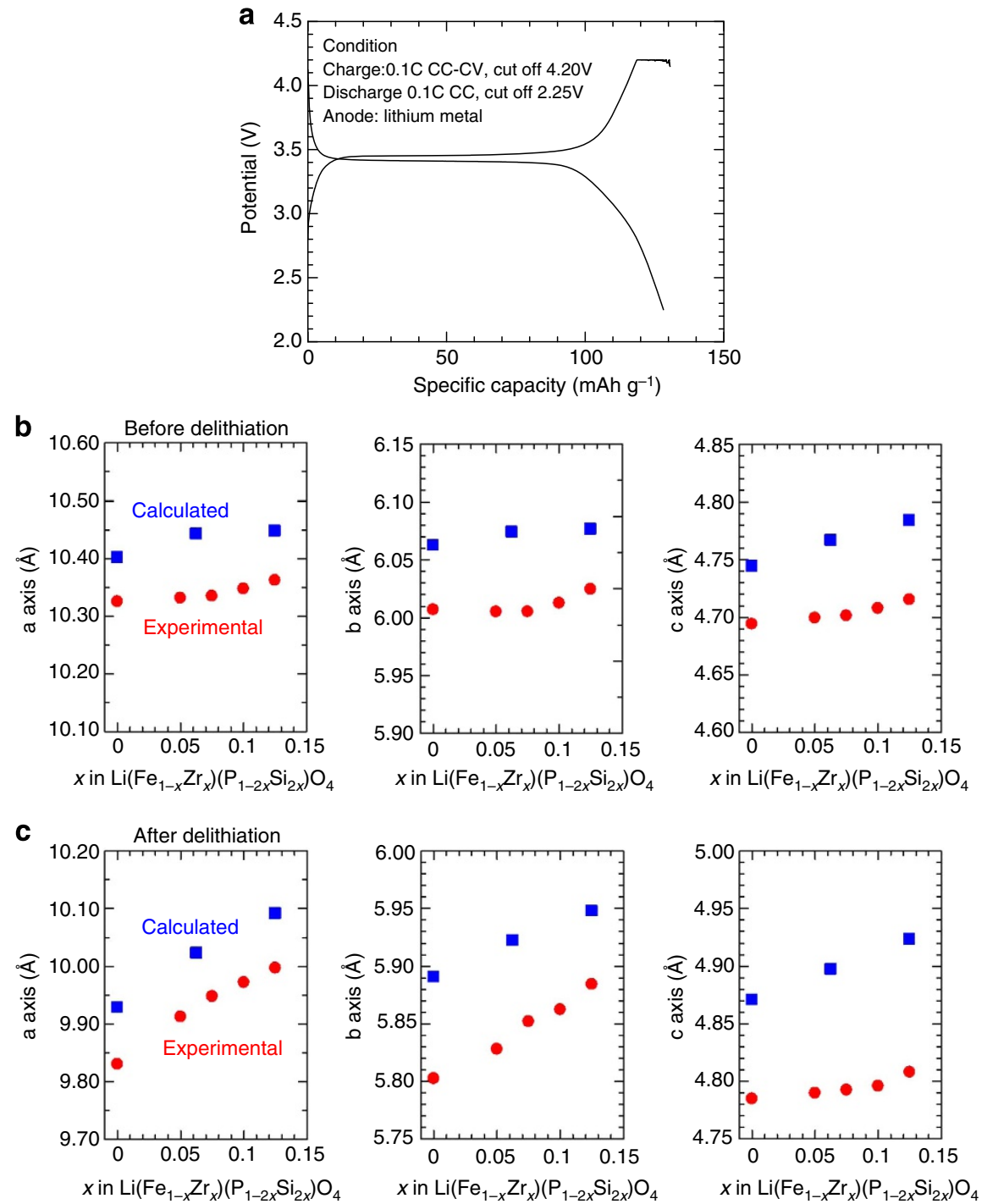

Figure 4 | Charge/discharge experiments with Z2S cathodes. (a) Charge and discharge curves for a beaker-type cell with $\mathrm{Li}_{(}\left(\mathrm{Fe}_{1-x} \mathrm{Zr}_{x}\right)\left(\mathrm{P}_{1-2 x} \mathrm{Si}_{2 x}\right) \mathrm{O}_{4}$ cathode of $x=0.125$. (b) Experimental and calculated lattice parameters of Z2S samples as a function of the solute concentration before delithiation and (c) after delithiation. Red circles and blue squares correspond to experimental and calculated results, respectively.

a

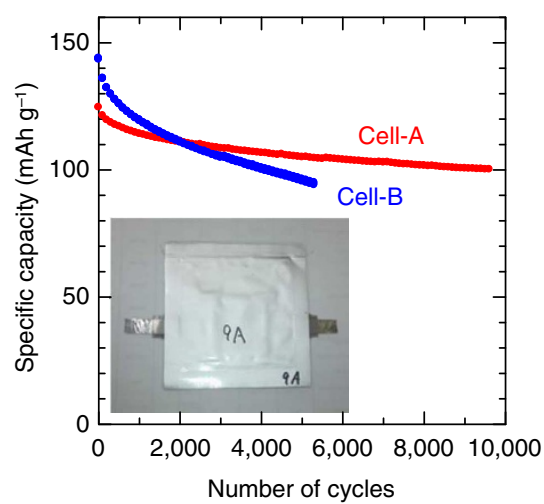

b

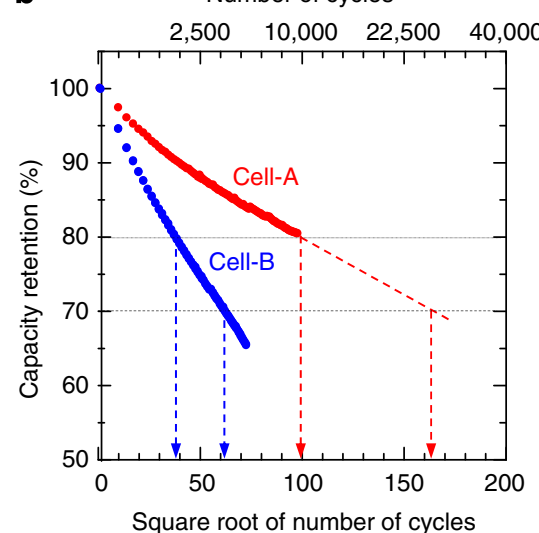

Figure 5 | Cycle life experiments with Z2S cathode. (a) The specific capacity of two pouch cells with pristine and Z2S $(x=0.050)$ cathodes as a function of number of charge/discharge cycles. An inset photo shows an aluminum-laminate pouch cell used for the cycle-life performance tests. (b) The capacity retention plotted against the square root of the number of cycles. Red and blue circles correspond to Cell-A and -B, respectively. 
$\mathrm{P}$ sites with $\mathrm{Zr}$ and $\mathrm{Si}$, respectively, by $x=0.125$ reduced the lattice RVC by $40 \%$; this was verified experimentally. The observed planar mismatch of bc planes of the substituted samples was as low as $0.3 \%$, which was significantly smaller than that of the pristine sample, $1.5 \%$. Electrochemical tests found that the rate capability of the cell with the co-substituted LFP was almost the same as that with the pristine LFP. The cycle life tests performed in a full cell configuration with a graphite anode showed that the cycle life of the cell containing the optimized Z2S $(x=0.050)$ cathode outperforms the cell containing the standard pristine cathode by a factor of 5 , and the estimated cycle life for $70 \%$ capacity retention was 25,000 cycles. This approach of screening materials using a large set of DFT is useful for the exploration of a large chemical compositional space. Accelerated discovery of suitable materials can therefore be performed and specific compositions can be targeted to confirm the results experimentally.

\section{Methods}

First-principles calculations. Calculations were made for all possible solute arrangements within the unit cell composed of four formula units ( 28 atoms for LFP). As for the substituted LFP, one of the four Li atoms in the unit cell was substituted by cations of six elements $\left(\mathrm{Li}^{+}, \mathrm{Na}^{+}, \mathrm{K}^{+}, \mathrm{Mg}^{2+}, \mathrm{Ca}^{2+}, \mathrm{Sr}^{2+}\right)$. One of the four Fe atoms was substituted by cations of 21 elements $\left(\mathrm{Mg}^{2+}, \mathrm{Ca}^{2+}\right.$, $\mathrm{Sr}^{2+}, \mathrm{Mn}^{2+}, \mathrm{Fe}^{2+}, \mathrm{Co}^{2+}, \mathrm{Ni}^{2+}, \mathrm{Cu}^{2+}, \mathrm{Zn}^{2+}, \mathrm{Sc}^{3+}, \mathrm{Y}^{3+}, \mathrm{Cr}^{3+}, \mathrm{Al}^{3+}, \mathrm{Ga}^{3+}$, $\left.\mathrm{In}^{3+}, \mathrm{Ti}^{4+}, \mathrm{Zr}^{4+}, \mathrm{Ge}^{4+}, \mathrm{Sn}^{4+}, \mathrm{V}^{5+}, \mathrm{Nb}^{5+}\right) . \mathrm{P}$ was substituted by cations of five elements $\left(\mathrm{Al}^{3+}, \mathrm{Ga}^{3+}, \mathrm{Si}^{4+}, \mathrm{P}^{5+}, \mathrm{V}^{5+}\right)$. The number of the substituted atoms was determined so that the formal charge of $\mathrm{Fe}$ is +2 . The delithiated states were constructed by removing $\mathrm{Li}$ atoms. The maximum number of removed $\mathrm{Li}$ atoms was determined so that the formal charge of Fe was at most +3 and those of the other elements were unchanged. All possible arrangements of the solute atoms were examined within the unit cell, and the most stable arrangement was selected to estimate the lattice constants for each set of the solute elements. The total number of DFT calculations was $\sim 2,000$.

First-principles DFT calculations were performed using the plane-wave basis projector-augmented wave method implemented in VASP code ${ }^{15}$. The plane-wave basis set was determined with a cutoff energy of $400 \mathrm{eV}$ for initial screening (Fig. 1). Additional calculations shown in Figs 2 and 4 were made with the cutoff energy of $500 \mathrm{eV}$. Integral in the reciprocal space was evaluated by the Gaussian smearing technique with a smearing parameter of $0.1 \mathrm{eV}$ and a $2 \times 3 \times 3$ mesh. Spin polarization was considered assuming collinear and parallel magnetic structures. The exchange-correlation interaction was treated by the generalized gradient approximation $^{16}$ with the Hubbard model correction $(\mathrm{GGA}+U)^{17}$. We used $\mathrm{U}$-parameters of 2, 2, 3, 4, 4, 4 and $5 \mathrm{eV}$ for Ti, V, Cr, Mn, Fe, Co and $\mathrm{Ni}$, respectively. The $U$-parameters were not used for the rest of the elements. Atomic positions and lattice constants were optimized until the residual forces and stresses, respectively, became smaller than $0.02 \mathrm{eV} / \AA$ and $2 \mathrm{GPa}$ for the initial screening (Fig. 1), and $0.02 \mathrm{eV} / \AA$ and $0.2 \mathrm{GPa}$ for the additional calculations (Figs 2 and 4).

Sol-gel synthesis. Samples were prepared by using the sol-gel possessing mediated by epoxides ${ }^{18,19}$. A conclusive advantage of the epoxide-mediated technique is that it allows the use of common metal salts as the sol-gel precursors, eliminating the need for highly reactive metal alkoxides. This technique has also proven to be useful in designing the precursor gels of highly homogensous complex oxides ${ }^{20-23}$. In this study, lithium acetate $\left(\mathrm{CH}_{3} \mathrm{COOLi}\right)$, iron nitrate nonahydrate $\left(\mathrm{Fe}\left(\mathrm{NO}_{3}\right)_{3}\right.$ $\left..9 \mathrm{H}_{2} \mathrm{O}\right)$, zirconium chloride $\left(\mathrm{ZrCl}_{4}\right)$, tetraethyl orthosilicate $\left(\mathrm{Si}\left(\mathrm{OC}_{2} \mathrm{H}_{5}\right)_{4}\right)$ and phosphoric acid $\left(\mathrm{H}_{3} \mathrm{PO}_{4}\right)$ were used as the sources of inorganic components, and ethanol was used as the solvent. Propylene oxide (PO) was added as a proton scavenger to promote gelation. All the reactants and solvents were reagent grade and were used as received. The typical molar ratio in the starting composition was $\mathrm{CH}_{3} \mathrm{COOLi}: \mathrm{Fe}\left(\mathrm{NO}_{3}\right)_{3} \cdot 9 \mathrm{H}_{2} \mathrm{O}: \mathrm{ZrCl}_{4}: \mathrm{Si}\left(\mathrm{OC}_{2} \mathrm{H}_{5}\right)_{4}: \mathrm{H}_{3} \mathrm{PO}_{4}$ : ethanol: $\mathrm{PO}=1$ : $1-x: x: 2 x: 1-2 x: 26.7: 27$ so as to fabricate samples with the composition of $\mathrm{Li}\left(\mathrm{Fe}_{1-x} \mathrm{Zr}_{x}\right)\left(\mathrm{P}_{1-2 x} \mathrm{Si}_{2 x}\right) \mathrm{O}_{4}$ upon calcination. The samples were prepared as follows. First, the cation sources were dissolved into ethanol under ambient atmosphere to give a homogeneous solution. Then, PO was added dropwise to the transparent solution under stirring. After that, the resultant solution was allowed to gel in a closed container at $40^{\circ} \mathrm{C}$ for $24 \mathrm{~h}$, and the wet gel was dried at $40^{\circ} \mathrm{C}$. The dried gel was ground in a mortar and calcined at $550{ }^{\circ} \mathrm{C}$ for $12 \mathrm{~h}$ under nitrogen atmosphere. Scanning electron microscopy observation of the final products found that the particle diameters were $\sim 0.1 \mu \mathrm{m}$ for all samples.

XRD refinements. Rietveld refinements ${ }^{14}$ were made for $\mathrm{Z} 2 \mathrm{~S}$ samples with a constriction that $\mathrm{Si}$ substitutes only $\mathrm{P}$ because $\mathrm{Si}$ is most likely to take only fourfold coordination. The occupation factors of $4 \mathrm{a}$ ( $\mathrm{Li}$ site) and $4 \mathrm{c}$ (Fe site) were then determined. Since the occupation factor for $\mathrm{Li}$ at $4 \mathrm{a}$ was close to unity, factors for $\mathrm{Fe}$ and $\mathrm{Zr}$ at $4 \mathrm{a}$ were indistinguishable. The occupation factor for $\mathrm{Li}$ at $4 \mathrm{c}$ was not able to be resolved, either.

Electrochemical tests. A beaker-type three-electrode cell was used for the delithiation. The working electrode was fabricated by mixing of the cathode powder, electronic conductor and binder at a ratio of 100:10:10 by weight. Acetylene black (Denkikagaku Kogyo) was used for the electronic conductor, and polyvinylidene difluoride (PVdF, Kureha) was used for the binder. In order to make the electrode, the mixture was dissolved in $N$-methyl pyrrolidone, and then cast on aluminium foil of $20 \mu \mathrm{m}$ thick. The electrode was dried at $80^{\circ} \mathrm{C}$ in air and pressed to increase the electrode density. Lithium metal foil was used for the counter and reference electrodes. The electrolyte was a $1 \mathrm{M}$ solution of $\mathrm{LiPF}_{6}$ in mixture of ethylene carbonate (EC) and dimethyl carbonate (DMC) with a 2:1 volume ratio (LBG-00938 $\mathrm{LiPF}_{6}, \mathrm{EC} / \mathrm{DMC}$, Kishida Chemical Corp., Ltd.). Charge and discharge were carried out at $0.1 \mathrm{C}$ rate between $2.25 \mathrm{~V}$ as the lower limit and $4.20 \mathrm{~V}$ as the upper limit at the constant temperature of $25^{\circ} \mathrm{C}$. $1 \mathrm{C}$ is defined as $170 \mathrm{~mA} \mathrm{~g}^{-1}$ for all samples for simplicity.

An aluminium-laminate pouch cell was used for cycle-life performance tests. The cathode was fabricated by the same procedures as mentioned above. The electrode was cut into $20 \mathrm{~mm} \times 20 \mathrm{~mm}$ square sheet and aluminium leads $(50 \mathrm{~mm} \times 5 \mathrm{~mm} \times 0.1 \mathrm{~mm})$ were welded as cathode leads. The mixture of a natural graphite (Hitachi Chemical) and binder (PVdF, Kureha) was dissolved in $\mathrm{N}$-methyl pyrrolidone at the ratio of 100:10, and then cast on $12 \mu \mathrm{m}$ of copper foil. The electrode was dried at $80{ }^{\circ} \mathrm{C}$ in air and pressed to increase the electrode density. This anode electrode was cut into $22 \mathrm{~mm} \times 22 \mathrm{~mm}$ square sheet and nickel leads $(50 \mathrm{~mm} \times 5 \mathrm{~mm} \times 0.1 \mathrm{~mm})$ were welded as anode leads. The cathode electrode, a polypropylene separator (Celgard, Polypore) and anode electrode were stacked and then put into an aluminium-laminate pouch. The electrolyte as mentioned above was poured into the aluminium-laminate pouch. This pouch was sealed using vacuum sealer to avoid permeation of moisture. Charge and discharge were carried out at $1 \mathrm{C}$ rate between $2.00 \mathrm{~V}$ as the lower limit and $3.80 \mathrm{~V}$ as the upper limit at the constant temperature of $25^{\circ} \mathrm{C}$. $0.1 \mathrm{C}$ charge and discharge were also carried out every 100 cycles to measure the capacity retention.

\section{References}

1. Padhi, A. K., Nanjundaswamy, K. S. \& Goodenough, J. B. Phospho-olivines as positive-electrode materials for rechargeable lithium batteries. J. Electrochem. Soc. 144, 1188-1194 (1997).

2. Yamada, A., Chung, S. C. \& Hinokuma, K. Optimized $\mathrm{LiFePO}_{4}$ for lithium battery cathodes. J. Electrochem. Soc. 148, A224-A229 (2001).

3. Service, R. F. Materials scientists look to a data-intensive future. Science 335, 1434-1435 (2012).

4. Ceder, G. Opportunities and challenges for first-principles materials design and applications to Li battery materials. MRS Bull. 35, 693-701 (2010).

5. Jain, A. et al. Commentary: the materials project: a materials genome approach to accelerating materials innovation. APL Mat. 1, 011002 (2013).

6. Curtarolo, S. et al. The high-throughput highway to computational materials design. Nat. Mater. 12, 191-201 (2013).

7. Balachandran, P. V., Broderick, S. R. \& Rajan, K. Identifying the 'inorganic gene' for high-temperature piezoelectric perovskites through statistical learning Proc. R. Soc. A 467, 2271-2290 (2011).

8. Fujimura, K. et al. Accelerated materials design of lithium superionic conductors based on first-principles calculations and machine learning algorithms. Adv. Energy Mater. 3, 980-985 (2013).

9. Carrete, J., Li, W., Mingo, N., Wang, S. \& Curtarolo, S. Finding unprecedentedly low-thermal-conductivity half-Heusler semiconductors via high-throughput materials modeling. Phys. Rev. X 4, 011019 (2014).

10. Delmas, C., Maccario, M., Croguennec, L., Le Cras, F. \& Weill, F. Lithium deintercalation in $\mathrm{LiFePO}_{4}$ nanoparticles via a domino-cascade model. Nat. Mater. 7, 665-671 (2008).

11. Wang, D. Y., Wu, X. D., Wang, Z. X. \& Chen, L. Q. Cracking causing cyclic instability of $\mathrm{LiFePO}_{4}$ cathode material. J. Power Sources 140, 125-128 (2005).

12. Chung, S. Y., Bloking, J. T. \& Chiang, Y.-M. Electronically conductive phospho-olivines as lithium storage electrodes. Nat. Mater. 1, 123-128 (2002)

13. Meethong, N., Kao, Y.-H., Speakman, S. A. \& Chiang, Y.-M. Aliovalent substitutions in olivine lithium iron phosphate and impact on structure and properties. Adv. Funct. Mater. 19, 1060-1070 (2009).

14. Izumi, F. \& Momma, K. Three-dimensional visualization in Powder Diffraction. Solid State Phenom. 130, 15-20 (2007).

15. Kresse, G. \& Furthmüller, J. Efficient iterative schemes for ab initio total-energy calculations using a plane-wave basis set. Phys. Rev. B 54, 11169-11186 (1996)

16. Perdew, J. P., Burke, K. \& Ernzerhof, M. Generalized gradient approximation made simple. Phys. Rev. Lett. 77, 3865-3868 (1996).

17. Dudarev, S. L., Botton, G. A., Savrasov, S. Y., Humphreys, C. J. \& Sutton, A. P. Electron-energy-loss spectra and the structural stability of nickel oxide: An LSDA + U study. Phys. Rev. B 57, 1505-1509 (1998). 
18. Gash, A. E. et al. Use of epoxides in the sol-gel synthesis of porous iron(III) oxide monoliths from Fe(III) salts. Chem. Mater. 13, 999-1007 (2001).

19. Itoh, $\mathrm{H}$. et al. Preparation of $\mathrm{SiO}_{2}-\mathrm{Al}_{2} \mathrm{O}_{3}$ gels from tetraethoxysilane and aluminum-chloride -a new sol-gel method using propylene-oxide as a gelation promoter. J. Ceram. Soc. Jpn 101, 1081-1083 (1993).

20. Chervin, C. N. et al. Aerogel synthesis of yttria-stabilized zirconia by a non-alkoxide sol-gel route. Chem. Mater. 17, 3345-3351 (2005).

21. Tokudome, Y. et al. Sol-gel synthesis of macroporous YAG from ionic precursors via phase separation route. J. Ceram. Soc. Jpn 115, 925-928 (2007).

22. Tokudome, Y., Miyasaka, A., Nakanishi, K. \& Hanada, T. Synthesis of hierarchical macro/mesoporous dicalcium phosphate monolith via epoxidemediated sol-gel reaction from ionic precursors. J. Sol-Gel Sci. Technol. 57, 269-278 (2011).

23. Hasegawa, G. et al. Facile preparation of monolithic $\mathrm{LiFePO}_{4} /$ carbon composites with well-defined macropores for a lithium-ion battery. Chem. Mater. 23, 5208-5216 (2011).

\section{Author contributions}

M.N., Y.Ko. and I.T. proposed the idea and the strategy for the computational and experimental works and wrote the paper. T.O., Y.Ka., K.O. and Y.Ko. performed computational works. T.S., S.E., M.N., S.M., K.F. and K.T. performed synthesis experiments. T.S., S.E., K.O. and M.N. made electrochemical measurements. All authors discussed the results and commented on the manuscript.

\section{Additional Information}

Supplementary Information accompanies this paper at http://www.nature.com/ naturecommunications

Competing financial interests: The authors declare no competing financial interests.

Reprints and permission information is available online at http://npg.nature.com/ reprintsandpermissions/

How to cite this article: Nishijima, M. et al. Accelerated discovery of cathode materials with prolonged cycle life for lithium-ion battery. Nat. Commun. 5:4553 doi: $10.1038 /$ ncomms5553 (2014). 